\title{
Study of motility and bacterial interactions during biofilm formation of two specie bacterial consortia developed by Bacillus subtilis, Bacillus cereus or Alkali gene faecalis under salt stress
}

\author{
Tayyiba Akram* and Aisha Waheed Qurashi \\ Department of Biology, Lahore Garrison University, Lahore-Pakistan \\ *Corresponding author's email: Tayyibaakram123@gmail.com
}

\section{Citation}

Tayyiba Akram* and Aisha Waheed Qurashi. Study of motility and bacterial interactions during biofilm formation of two specie bacterial consortia developed by Bacillus subtilis, Bacillus cereus or Alkali gene faecalis under salt stress. Pure and Applied Biology. Vol. 7, Issue 1, pp271-281. http://dx.doi.org/10.19045/bspab.2018.70033

\begin{tabular}{llll}
\hline \hline Received: 18/11/2017 & Revised: 07/02/2018 & Accepted: 10/02/2018 & Online First: 16/02/2018 \\
\hline \hline
\end{tabular}

\section{Abstract}

Microbes present in soil exist in close association to other microbial species and formulate the shape of microbial communities in soil. This interaction can be in the form of positive or negative towards each other. Present study deals with analysis of interaction and motility behavior and biofilm formation during monoculture and two-specie culture (on the basis of salt tolerance) among previously isolated strains HFF (Bacillus cereus KY435717), HFP (Bacillus subtilis) and AQ-1 (Alkali gene faecalis KR052007) from plant or soil. The results showed that strain AQ-1 showed highest cell densities at $0.5 \mathrm{M} \mathrm{NaCl}$ stress while HFF and HFP showed best growth at 1.5 $\mathrm{M} \mathrm{NaCl}$ stress. Biofilm formation pattern in single specie culture was relatively high in all three strains when compared to two-specie culture of A.faecalis with B.cereus or A.faecalis with B.subtilis experiment showing antagonistic effects species towards each other in co-culture. Despite lower cell densities recorded AQ-1, individual cell densities and biofilm formation was highest at $1.5 \mathrm{M} \mathrm{NaCl}$ stress in co culture showing the benefit of co culturing. Bacterial motility patterns were also determined on the basis of twitching, swimming and swarming assay. Interdependence of motility behavior of bacterial strains was recorded. Moreover, twitching motility was correlated to swimming and swarming. Neither was motility behavior was associated with biofilm formation. Results of current study showed that A.faecalis improve its survival in two specie biofilms with B.cereus and B.subtilis at $1.5 \mathrm{M} \mathrm{NaCl}$ stress and facilitates the improvement in plant growth. Future implication of this study dealing with microbial interaction will pave the way for further understanding of the interactions of microbes associated with plants.

Keywords: Alkali gene faecalis; Bacillus cereus; Bacillus subtilis; Biofilm; Motility

Introduction

In environment no organism can live without interacting with environment. In agricultural land where complex compounds are easily available, microbes rarely exist as single species. The development of biofilm 
formation with diverse morphology and density is commonly observed in soil $[1,2]$. Close association of bacterial species in soil can shape the existence and diversity of microbial communities in fluctuating conditions of soil. Microbial biofilms are used to study social interactions and to examine how these interactions are shaped in time and space. Study have reported that bacterial interactions in the communities may be beneficial by providing growth factors to each other or by inhibiting the growth by producing antibiotics, bacteriocin or toxic metabolites and decides the fate of species in environment [3]. Biofilms are examples of a cooperative interaction where bacterial communities are protected from environmental stress like salinity [4], predation or exposure to bacteriocin and antibiotics [5] extracellular matrix further strengthens this association by providing protection to this consortia. Bacterial biofilms are made by groups of bacteria that are protected in the self-generated extracellular polymeric substances (EPS) [6]. EPS produced by microbial species are used by other species which are not well efficient in producing this EPS.

In bacterial interactions, attachment of microbes to different surfaces offers the microbes an advantage to have more availability of nutrients. EPS also play a role in microbial adherence [7]. However, if some species are non-producers they may be replaced with over producing EPS species [8]. Bacteria cells are attached either on the living or non-living surfaces as biofilms and they live as the free floating or the attached cells [9]. Biofilms formed by the bacteria are made up of multifaceted bacterial cells that are packed in the sheath of polysaccharides containing networks for nutrient and water passage [10]. Present life style of microbial cells in the form of biofilm is important for the complex understandings of socio microbiological levels of biofilm development and quorum sensing [11], environmental opportunistic pathogens and human health related infections [12]. A notable amount of knowledge has been developed in 20-30 years regarding the bacterial biofilm formation which shows that the biofilms are a network of bacterial cells attached and embedded into self-produced matrix and they are attached to living or nonliving surfaces, are different from the free floating or planktonic cells in a multiple ways. [13]. Quorum sensing is well-defined as a cell-cell association process used by some bacterial taxa to form gene expression and behavior in sets, becomes basis of rise in population [14]. Physical procedures and supportive activities of a number of bacteria are monitored by a process known as quorum sensing (QS), in which bacterial cells communicate with one another by discharging, detecting and acting to small diffusible signal molecules [15]. It consists the manufacture, innovation, and reaction to extracellular signal molecules commonly known as autoinducers (AIs) [16]. AIs collected in the atmosphere as the bacterial population quantity becomes greater than before, and bacteria check this info to make changes in their cell numbers and collectively change gene expression [17].

Teamwork behavior or clash of microorganisms within communities ultimately plays the decisive role to shape microbial communities [13]. Previously many reports have described the interactions between microbes from oral site [18, 19] however, the multispecies biofilms in soil bacteria has been described at very initial basis.

On this basis present research the work is focused to drive the knowledge on the interactions that may initiate the bacterial biofilm communities. These interactions can be certainly helpful for plant soil relations. The study of bacterial ecosystem and interactions particularly those attained from 
environment are useful in understanding the capability of bacteria to retain in the soil.

Materials and methods

\section{Bacterial strains}

Previously isolated and characterised bacterial strains HFF (Bacillus cereus KY435717) from fresh fruit, HFP (Bacillus subtilis) isolated from rotten fruit and AQ-1 (Alkali gene faecalis KR052007) isolated from soil were characterized and used in this study.

\section{Inoculum preparation}

Inoculum was prepared by growing bacterial cultures at $0.5 \mathrm{M} \mathrm{L}$-Agar at $37^{\circ} \mathrm{C}$ for 24 hours. Loopful of bacterial inoculum was taken and resuspended into sterilized L- broth, incubated at $37^{\circ} \mathrm{C}$ for 24 hours and finally the absorbance of inoculum was adjusted at 0.5 (OD 600nm) to confirm equal cell masses.

Screening of bacterial strains for salt tolerance

Bacterial strains were screened for their ability to tolerate different salt concentrations (0.5M, 1.5M and $3 \mathrm{M})$ in L-agar and L-broth.

\section{Swimming, swarming and twitching}

The motility assays were carried out by following the method of [20]. The plates for swimming were prepared by using swimming media (1\% Trypton, $0.5 \% \mathrm{NaCl}$ and $0.3 \%$ Agar) and point inoculation was done using $10 \mu \mathrm{L}$ of fresh bacterial culture developed in $\mathrm{L}$ broth and OD adjusted to 0.5 (OD600). Plates were incubated for 16 hours at $37^{\circ} \mathrm{C}$. Media for swarming was prepared $(0.5 \%$ Agar, $8 \mathrm{~g}$ nutrient broth, $5 \mathrm{~g}$ dextrose per litre). Plates were dried in sterilized environment in laminar air flow by opening them half in laminar air flow for 10 to 15 minutes until they become solidified. Plates were prepared and inoculated on the surface with bacteria. After inoculation plates were incubated for 24 hours at $30^{\circ} \mathrm{C}$. Media for twitching assay was prepared by adding $1 \%$ agar. Prepared plates were stab inoculated by stabbing using single colony taken from the fresh culture. Inoculated plates were then incubated at $30^{\circ} \mathrm{C}$ for 24 hours. Motility patterns for twitching was observed by the formation of hazy and halo zones formed at the inoculation point by removing the agar and staining the attached cells using $1 \%$ aqueous crystal violet. Twitching pattern of strains was checked to know whether the bacterial cells are abundant enough to spread on the plates. Zones were recorded as [21], three groups were classified as intermediate $(5-20 \mathrm{~mm})$ positive or motile $(>20 \mathrm{~mm})$ or negative $(<5 \mathrm{~mm})$ depending on zone size.

Microscopic image analysis of motility

For image analysis of the motility assays swimming, swarming and twitching plates were observed under light microscope (MEIJI). For visualization of colony edges twitching zones by microscopy and stained edges with crystal violet showed that they were somewhat irregular. Micrographs were observed at 40X and $100 \mathrm{X}$ magnifications.

\section{Biofilm formation assay}

Biofilm formation was observed in mono and mix culture inoculations under varying salt stress conditions. For quantification of bacterial biofilm the method of [22] was used after modification to measure tightly bound cells. The bacterial strains were inoculated (100 $\mu \mathrm{l}$; OD $600 \mathrm{~nm}$ of 0.5 ) in $10 \mathrm{ml}$ of broth with added $1.5 \mathrm{M}$ salt concentration and sterile polystyrene coupons having dimensions ( $3 \mathrm{~cm}$ length, $1 \mathrm{~cm}$ width). Inoculated media was incubated for 96 hours at $37^{\circ} \mathrm{C}$ without agitation. Growth of bacteria was taken by measuring OD at $600 \mathrm{~nm}$. After measuring $\mathrm{OD}$, the tubes were emptied and culture was wasted. Then $0.1 \%$ aqueous crystal violet was added in tubes and tubes were placed at room temperature for 20 minutes. Cells were stained with crystal violet and washed with $70 \%$ ethanol for 5 minutes. OD 570 for the attached cells stained with crystal violet was recorded to check biofilm formation. Biofilm formation values were counted as normalized values $=$ OD 570/OD $600 \mathrm{~nm}$ to ignore the difference 
between biofilm formation and bacterial growth.

\section{Microscopic image analysis}

Coupons were taken out from test tubes placed of biofilm development experiments, and treated aseptically. Coupons were washed with sterile distilled water and stained for 20 minutes with $0.1 \%$ crystal violet. After staining coupons were observed for microscopic image analysis using light microscope (MEIJI) attached with camera.

Plant growth promoting potential of bacterial strains

Certified seeds of Triticum aestivum Var. Uqab 2000 were obtained from Punjab seed corporation Lahore, Pakistan. Seeds were treated with $0.1 \% \mathrm{HgCl}_{2}$ solution for 5 minutes for sterilization. Seeds were then washed with sterile distilled water 2 to 3 times to remove all traces of disinfectant. Seeds were inoculated with bacterial cultures (OD 0.5 at $600 \mathrm{~nm}$ ) for 30 minutes. After that these seeds were potted in the pots having 100 gram moist sterilized garden soil. Five seeds were potted per pot. Pots were regularly watered to avoid moisture loss. The pots were retained in dark for 3 days until seeds germinated and then shifted to light for 12 days afterwards.

\section{Microscopic examination of plant roots}

Inoculated roots taken from seedlings were stained with Sudan III dye with the efficiency of staining lipids.

\section{Statistical analysis}

Statistical data analysis was carried out using IBM SPSS statistics 21 software. All experiments contain reported values that were the mean of three replicates. The results were recorded as mean values with standard error of means. Results of biofilm formation and motility experiments were tested for interdependence and calculated by Pearson's correlation coefficient.

\section{Results and discussion}

Formerly isolated (in Lab by Qurashi and coworkers) and characterized three bacterial strains HFF (Bacillus cereus KY435717), HFP (Bacillus subtilis) and AQ-1 (Alkali gene faecalis KR052007), were observed for salt tolerance using $0.5,1.5$ and $3 \mathrm{M}$ salt supplemented LB agar plates and L-broth (Figure 1). Bacterial growth was observed by taking absorbance (OD600 nm) in L-broth media at different salt concentrations i.e., 0.5 $\mathrm{M}, 1.5 \mathrm{M}$ and $3 \mathrm{M} \mathrm{NaCl}$. The growth of HFF (Bacillus cereus) and HFP (Bacillus subtilis) was higher at $1.5 \mathrm{M}$ as compared to strain AQ-1 (Alkaligene faecalis) that showed lesser growth at same concentration. Strain AQ-1 (Alkaligene faecalis) showed best growth at $0.5 \mathrm{M} \mathrm{NaCl}$ when compared to 1.5 $\mathrm{M}$ or $3 \mathrm{M}$ salt supplemented media.

On the basis of variable reaction of bacteria towards different salt concentrations, a two specie consortia was formulated and the result was recorded at high salinity i.e $1.5 \mathrm{M}$ $\mathrm{NaCl}$ stress. Increased salt concentration cause damage to cell toughness or its turgidity that is essential for the growth and activities of bacteria. To survive this stress, bacteria show different approaches over salt stress like biofilm formation [22]. B. cereus growth is reduced when presented to media having $\mathrm{NaCl}(0-10 \%)$

Motility behavior of all bacterial isolates was tested for twitching, swimming and swarming assay. Twitching pattern was visible in all the strains. Minimum zone was measured for AQ-1(Alkali gene faecalis). Twitch motility plates were also observed for image analysis using light microscope (MEIJI). For twitching microscopic analysis of colonies formed on twitch agar plates showed irregular margins (Figure 2). Twitching motility was observed as formation of halo diameter measurement zone formed away from the point of inoculation. No physical motility difference was observed for all the three strains showing variable response in strain AQ-1 (Alkali gene faecalis). It was also evident that strain AQ-1 (Alkali gene faecalis) showed medium 
motility. In swimming motility dendrites formation indicate the colony formation. (Figure 2) Motility pattern was observed on the plates by observing the diameter of motility from the point of inoculation towards periphery of plates. All the three strains showed the specific motility pattern. During bacterial culture incubation, the distance among the middle of the colony and the edge of the migrating colonies were measured. The distances observed in $\mathrm{cms}$ were different though, the highest diameter value was recorded in HFP (Bacillus subtilis). Swarming motility of strains showed a diffused ring expanding from the site of bacterial inoculation (Figure 2) Motility behavior for all bacterial isolates was tested for twitching, swimming and swarming assay. According to the zone sizes recorded by Vijayakumar et al. [21], three groups are characterized as intermediate (5$20 \mathrm{~mm}$ ) positive or motile (>20 mm) or negative $(<5 \mathrm{~mm})$ dependent on zone size. Smallest zone sizes were recorded for AQ1(Alkali gene faecalis) as compared to other bacterial strains. While all the three strains showed the positive reaction in swimming.
Swarming assay was performed for the observation of distances in $\mathrm{cm}$ however, the maximum diameter was recorded in HFP (Bacillus subtilis). All the bacterial strains showed twitching motility where the twitch zones formed was of variable sizes depending on the bacterial strain. AQ1(alkali gene fecalis) showed the minimum zone. B. subtilis swarming is organized by the swrA operon and also need the presence of the surfactant element surfactin [23]. On the basis of different response toward salt concentration, bacterial consortia biofilm formation was tested either between $A$. faecalis and B. subtilis or A. faecalis and $B$. cereus at $1.5 \mathrm{M} \mathrm{NaCl}$ stress. Biofilm formation was observed and determined in single species and mix specie cultures of three bacterial isolates. Biofilm formation between three bacterial strains was studied by co culturing of all three monoculture and also two combinations of three strains. Biofilm development by pure cultures was measured by taking absorbance of (biofilm) biofilm forming cells (OD 590) and compared to respective monoculture specie (Abs 590).

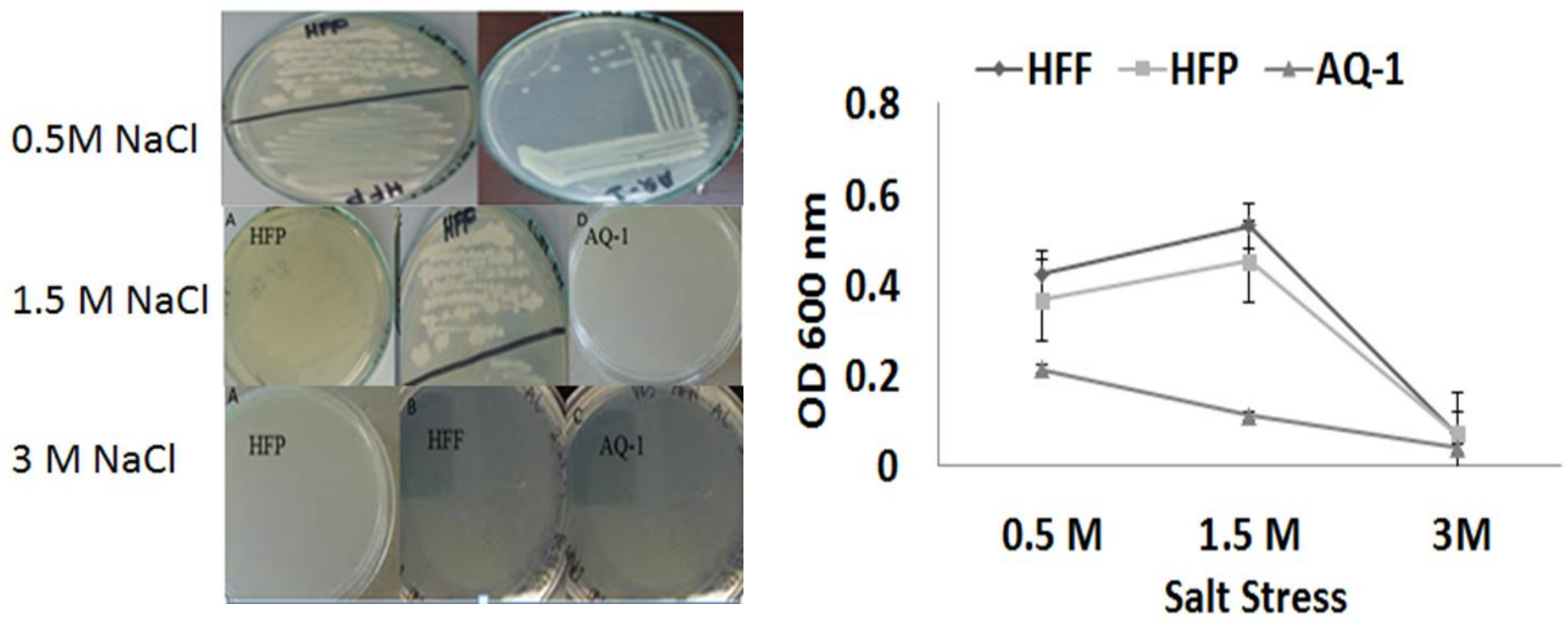

Figure 1. Growth frequency of bacteria at variable salt concentrations $(0.5,1.5$ and $3 \mathrm{M})$ $\mathrm{NaCl}$ supplemented LB agar plates 


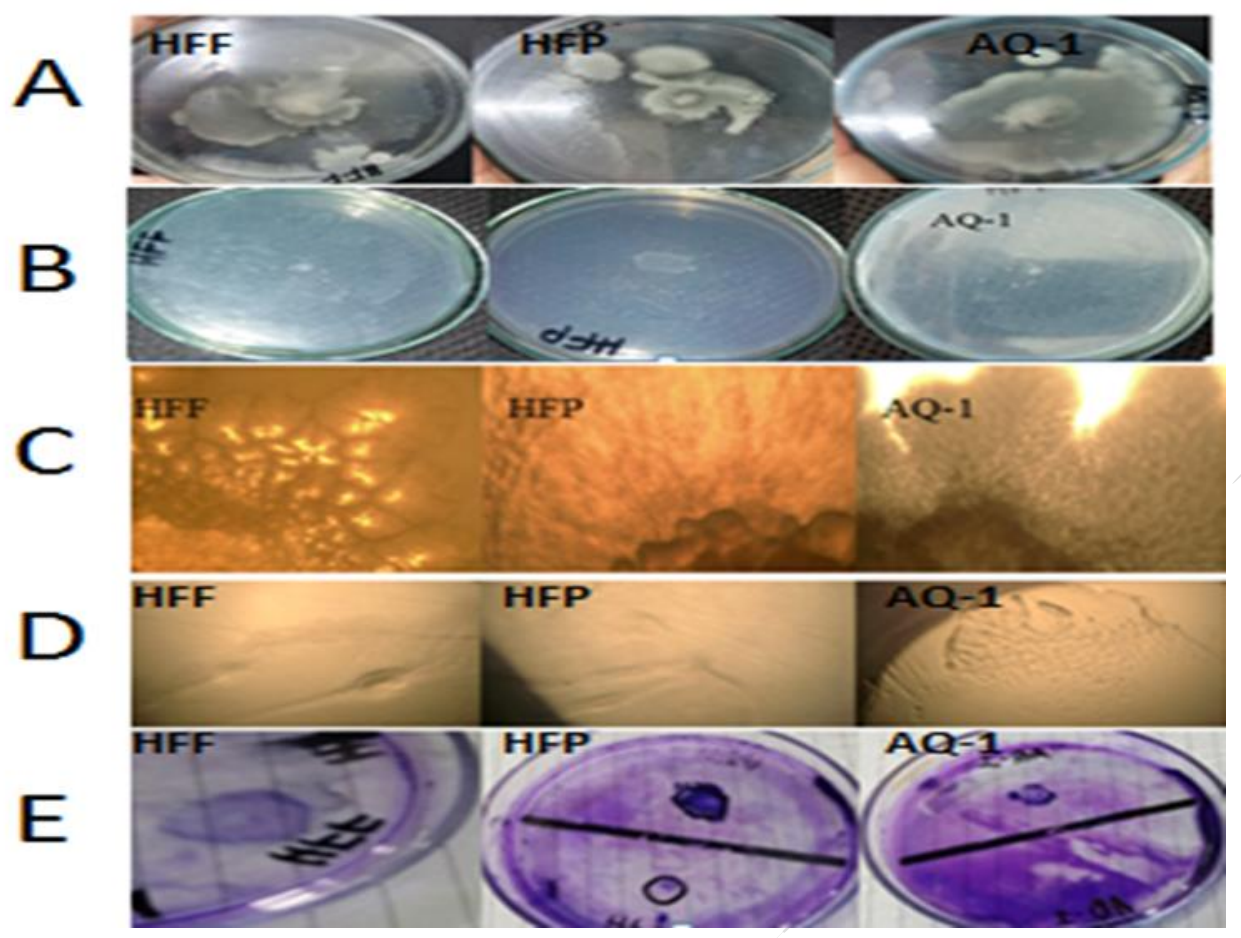

Figure 2. Motility behavior of bacterial strains (A) Swimming motility pattern of the strains (b) Swarming motility pattern of the strains. (C)Twitching plates showing colonies under light microscope (D) After removal of agar media from plate non stained regions (E) zones were stained with crystal violet and observed as dense clumps

In terms of monoculture the maximum bacterial biofilm was recorded for $\mathrm{HFF}$ (Bacillus cereus) as compared to AQ-1 (Alkali gene faecalis) while in mix culture bacterial biofilm was relatively reduced as compared to respective pure culture of HFF or AQ-1 or coculture (Figure $3 \& 4$ ). In terms of biofilm formation the monoculture of HFP (Bacillus subtilis) strain showed a good pattern when compared to strain AQ-1 (Alkali gene faecalis) while mix culture of the two strains showed moderate biofilm formation at $1.5 \mathrm{M}$ salt stress (Figure $3 \& 4$ ). Same results were recorded in image analysis. In mono-culture the arrangement of biofilm forming cells showed layers of biofilm in strain HFP (Bacillus subtilis) and there was very less biofilm formed by strain AQ-1(Alkali gene faecalis) as compared to HFP (Bacillus subtilis) but biofilm formation in mixed culture was relatively better. Evident cell clumps were recorded in co culture grouping as compared to pure culture of both strains Alkali gene faecalis (AQ-1) \& Bacillus subtilis (HFP). Best biofilm formation was studied when HFF (Bacillus cereus KY435717), HFP (Bacillus subtilis) and AQ-1 (Alkaligene faecalis KR052007) strains were seperately cultured while the co culturing of HFF (Bacillus cereus KY435717) and AQ-1 (Alkaligene faecalis KR052007) and HFP (Bacillus subtilis) and AQ-1 (Alkaligene faecalis KR052007) showed antagonistic effects which showed that these two antagonistically effects the growth of each another. This is dependent on the fact that during lack of connections cell thickness of single specie biofilm and multispecies biofilms is indistinguishable, so no further biofilm is shaped by different species societies than by single species societies when same supplements are offered unless cooperation causing synergistic impacts happen and, the best biofilm 
previous leads the biofilm [1]. In common habitats single species biofilms are very surprising; especially in single species countryside soils where small scale groups offered to natural issue can probably form into multispecies biofilms with increased bacterial mass and varied variety [1, 24]. Such conditions in bacterial domains are likely to encourage the advancement of complex connections between various species, while numerous past examinations have concentrated on interspecies relations inside oral microbial groups $[18,19,25,26]$, explore on different species biofilms made out of soil bacterial is still at its start. The biofilm formation pattern in monoculture and co-culture experiment showed that bacterial strains were antagonizing the effect of one another in co-culture e.g AQ-1(Alkali gene faecalis) and HFP (Bacillus subtilis) similar response was recorded when AQ-1 (Alkali gene faecalis) was grown in combination with HFF (Bacillus cereus) strain. Still it was considerable to describe that the rest of strains showed positive response in co culture.

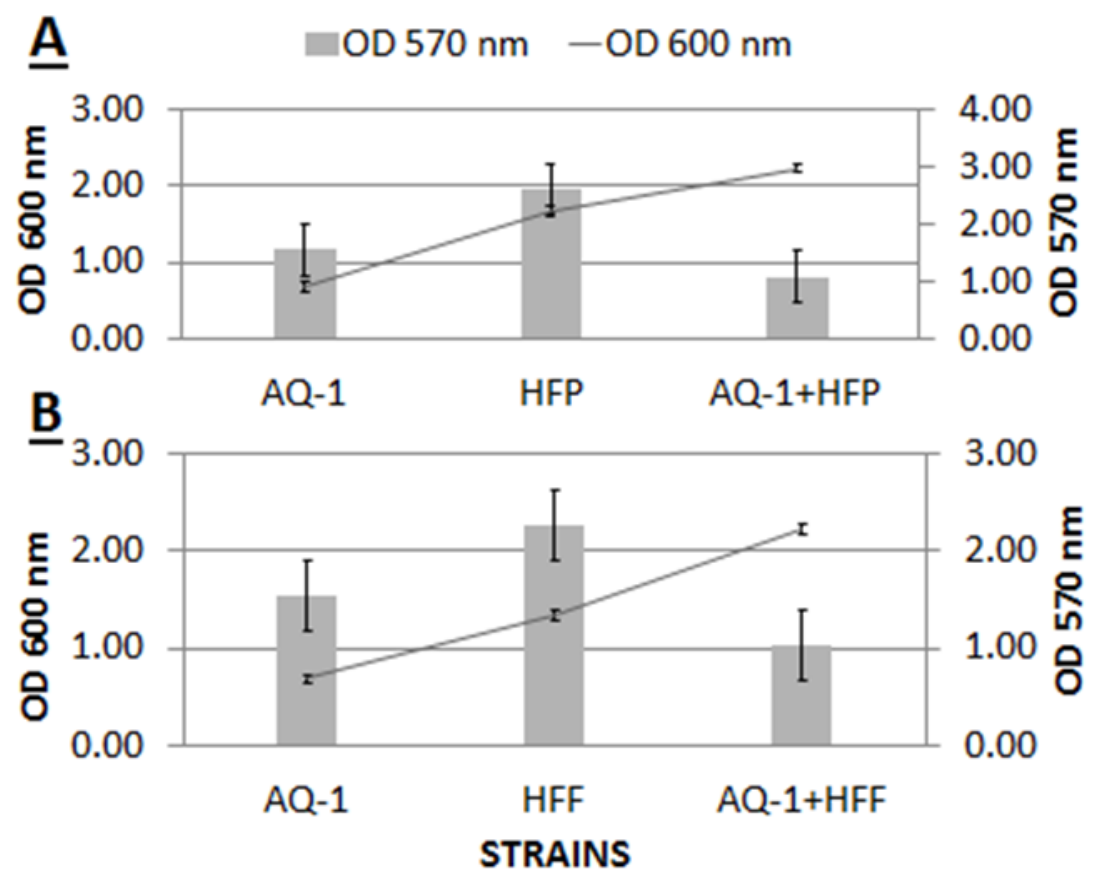

Figure 3. Growth and biofilm pattern of mono specie and two specie culture of (A) HFF (Bacillus cereus) and AQ-1 (Alkali gene faecalis) (B) HFP (Bacillus subtilis) and AQ-1 (Alkali gene faecalis) in

To check the effect of plant growth promoting potential of bacterial strains on seedlings, certified seeds of Triticum aestivum Var. Uqab 2000 were obtained from Punjab seed corporation Lahore. Seeds were inoculated with the three bacterial strains as monoculture and mix culture and grown for 15 days in plastic pots. Plant growth was recorded in terms of germination, root length, shoot length and seedling length in cms. In terms of germination $33 \%$ increase in germination was observed for each bacterial strain under salt concentration as compared to their respective non-inoculated control treatments. In terms of shoot length it was observed that maximum increment in shoot length was recorded for $\mathrm{HFF} 50 \%$ in the presence of salt as compared to the plants 
without salt stress. In case of root length it was observed that the roots of the plants under salt stress were increased in terms of length as compared to their control noninoculated plants. Highest increment in length parameter was recorded with strain AQ-183 \% as compared to rest of inoculation. Highest increase in seedling length was recorded with HFF \& AQ-1 $54 \%$ as compared to rest of bacterial inoculation (Figure 5, $6 \&$ 7). Bacillus subtilis is very important member of the Plant Growth Promoting Rhizobacterial (PGPR) having beneficial capabilities e.g. encouraging plant growth and monitoring of plant diseases [2729].

A

B
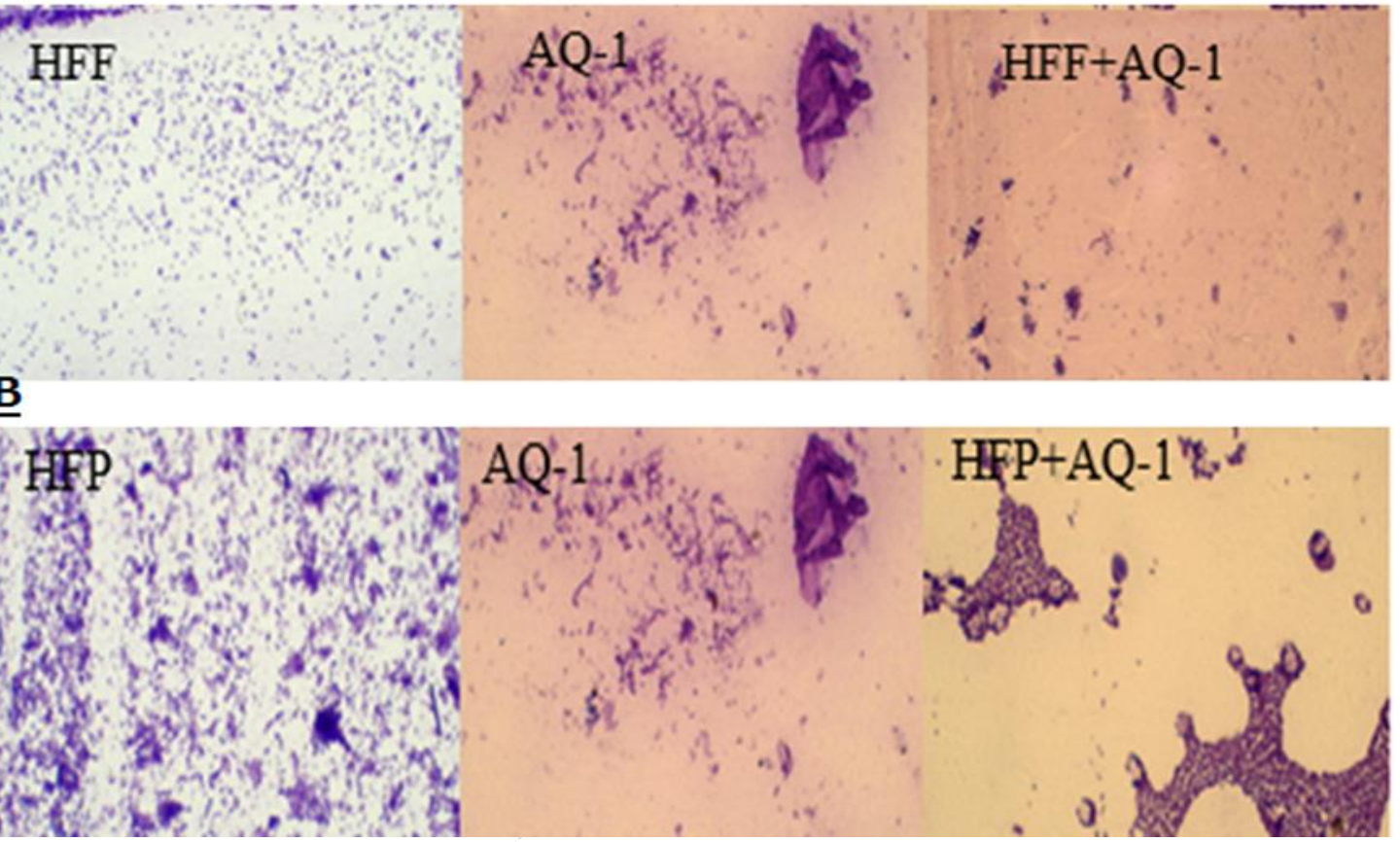

Figure 4. Polystyrene coupons showing biofilm formation in mono and mix culture of (A) HFF (Bacillus cereus) and AQ-1 (Alkali gene faecalis); (B) HFP (Bacillus subtilis) and AQ-1 (Alkali gene faecalis)

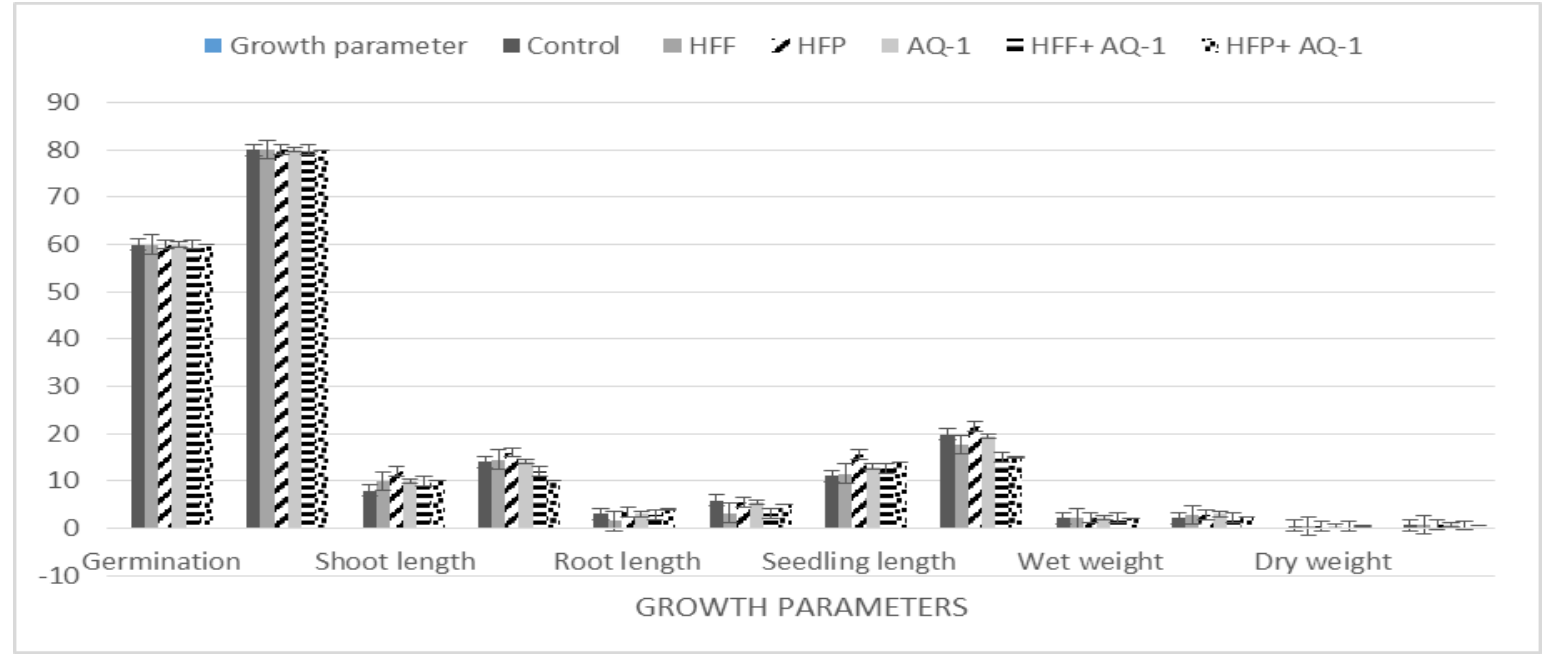

Figure 5. Graph showing different growth parameters at 100Mm $\mathrm{NaCl}$ 


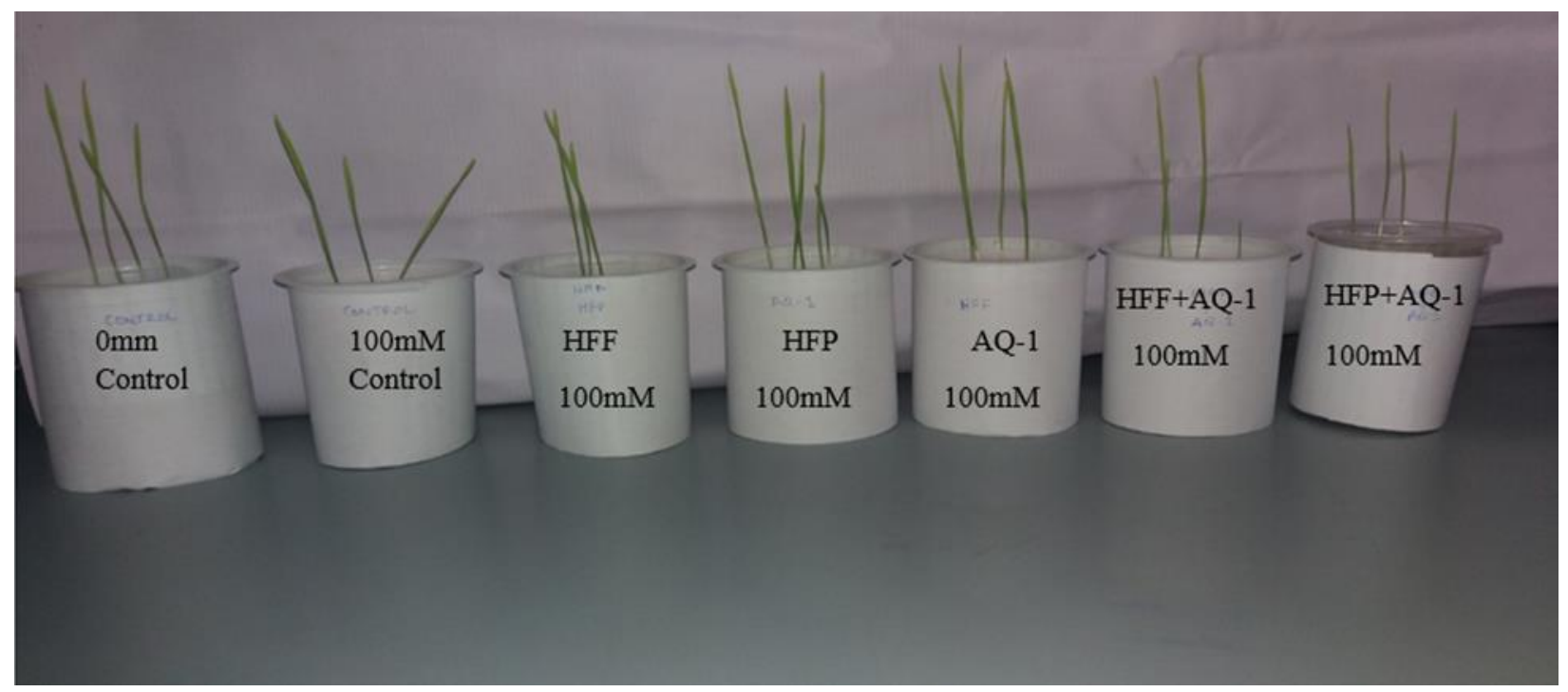

Figure 6. Pots showing germination of seeds after 10 days at $100 \mathrm{mM} \mathrm{NaCl}$ stress

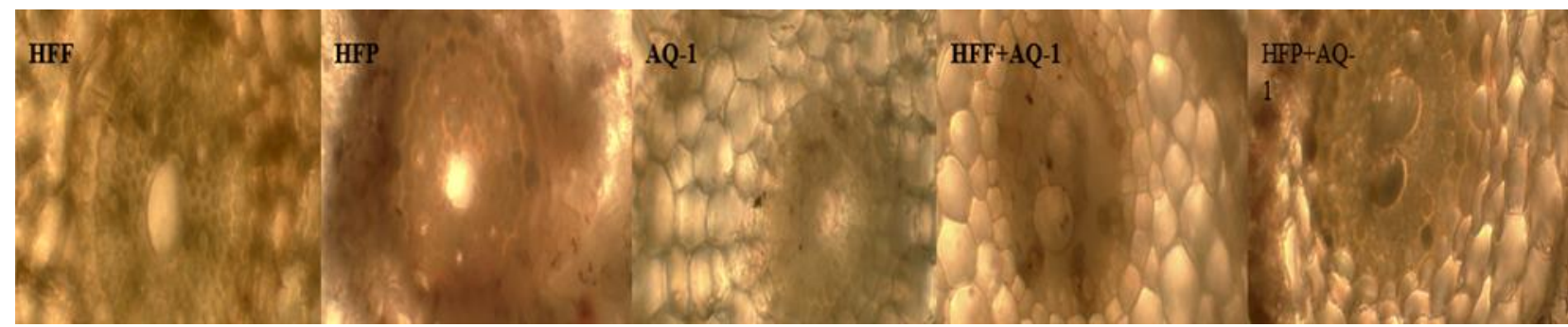

Figure 7. Plant root section cut staining with sudan III

\section{Conclusion}

Success of microbial community development is only possible by successful bacterial interactions that in turn can be beneficial for plant growth promotion under salt stress.

\section{Authors' contributions}

Conceived and designed the experiments: AW Qurashi \& T Akram, Performed the experiments: T Akram, Analyzed the data: T Akram \& AW Qurashi, Contributed materials/ analysis/ tools: T Akram, Wrote the paper: T Akram.

\section{References}

1. Burmolle M, Thomsen T, Fazli M, Dige I, Christensen L, Homoe P \& Moser C (2010). Biofilms in chronic infections-a matter of opportunity-monospecies biofilms in multispecies infections. Fems Immunol Med Mic 59(3): 324-336.
2. Ren D, Madsen JS, Sorensen SJ \& Burmolle M (2015). High prevalence of biofilm synergy among bacterial soil isolates in cocultures indicates bacterial interspecific cooperation. The ISME J 9(1): 81-89.

3. Galvez A, Abriouel H, Lopez RL \& Omar NB (2007). Bacteriocin-based strategies for food biopreservation. Int $J$ Food Microbiol 120(1): 51-70.

4. Giaouris E, Heir E, Hebraud M, Chorianopoulos N, Langsrud S, Moretro T \& Nychas GJ (2014). Attachment and biofilm formation by foodborne bacteria in meat processing environments: causes, implications, role of bacterial interactions and control by alternative novel methods. Meat Sci 97(3): 298-309.

5. Braga RM, Dourado MN \& Araujo WL (2016). Microbial interactions: ecology in 
a molecular perspective. Braz J Microbiol 47: 86-98.

6. Flemming HC, Wingender J, Szewzyk U, Steinberg P, Rice SA \& Kjelleberg S (2016). Biofilms: an emergent form of bacterial life. Nat Rev Microbiol 14(9): 563-575.

7. Donlan RM (2001). Biofilm formation: a clinically relevant microbiological process. Clin Infect Dis 33(8): 1387-1392

8. Habimana O, Semiao AJC \& Casey E (2014). The role of cell-surface interactions in bacterial initial adhesion and consequent biofilm formation on nanofiltration/reverse osmosis membranes. J Memb Sci 454: 82-96.

9. Talagrand-Reboul E. Jumas-Bilak E \& Lamy B (2017). The Social Life of Aeromonas through Biofilm and Quorum Sensing Systems. Front Microbiol 20 January

10. Donlan RM \& Costerton JW (2002). Biofilms: survival mechanisms of clinically relevant microorganisms. Clin Microbiol Rev 15(2): 167-193.

11. Claessen D, Rozen DE, Kuipers OP, Sogaard-Andersen L \& van Wezel GP (2014). Bacterial solutions to multicellularity: a tale of biofilms, filaments and fruiting bodies. Nat Rev Microbiol 12: 115-124.

12. Bjarnsholt T, Jensen P O, Jakobsen TH, Phipps R, Nielsen AK \& Rybtke MT (2010). Quorum sensing and virulence of Pseudomonas aeruginosa during lung infection of cystic fibrosis patients. PLoS ONE 5(4): e10115.

13. Hall-Stoodley L, Costerton JW \& Stoodley P (2004). Bacterial biofilms: from the natural environment to infectious diseases. Nat Rev Microbiol 2(2): 95-108.

14. Frederick MR, Kuttler C, Hense BA \& Eberl HJ (2011). A mathematical model of quorum sensing regulated EPS production in biofilm communities. Theor Biol Med Model 8(1): 8.

15. Li YH \& Tian X (2012). Quorum sensing and bacterial social interactions in biofilms. Sensors, 12(3): 2519-2538

16. Lazar V (2011). Quorum sensing in biofilms-how to destroy the bacterial citadels or their cohesion/power. Anaerobe 17(6): 280-285.

17. Rutherford ST \& Bassler BL (2012). Bacterial quorum sensing: its role in virulence and possibilities for its control. Cold Spring Harb Perspect Med 2(11): a012427.

18. Kuramitsu HK, He X, Lux R, Anderson MH \& Shi W (2007). Interspecies interactions within oral microbial communities. Microbiol Mol Biol Rev 71(4): 653-670.

19. Saito Y, Fujii R, Nakagawa KI, Kuramitsu HK, Okuda K \& Ishihara K (2008). Stimulation of Fusobacterium nucleatum biofilm formation by Porphyromonas gingivalis. Mol Oral Microbiol 23(1): 1-6.

20. Deziel E, Comeau Y \& Villemur R (2001). Initiation of biofilm formation byPseudomonas aeruginosa 57RP correlates with emergence of hyperpiliated and highly adherent phenotypic variants deficient in swimming, swarming, and twitching motilities. J Bacteriol 183(4): 11951204.

21. Vijayakumar S, Rajenderan S, Laishram S, Anandan, S, Balaji V \& Biswas I (2016). Biofilm formation and motility depend on the nature of the Acinetobacter baumannii clinical isolates Front public health 4.

22. Qurashi AW \& Sabri AN (2012). Bacterial exopolysaccharide and biofilm formation stimulate chickpea growth and soil aggregation under salt stress. Braz J Microbiol 43(3): 1183-1191. 
23. Calvio C, Celandroni F, Ghelardi E, Amati G, Salvetti S, Ceciliani F \& Senesi S (2005). Swarming differentiation and swimming motility in Bacillus subtilis are controlled by swrA, a newly identified dicistronic operon. J Bacteriol 187(15): 5356-5366.

24. Rodríguez SJ \& Bishop PL (2007). Three-dimensional quantification of soil biofilms using image analysis. Environ Eng Sci 24(1): 96-103.

25. Sharma A, Inagaki S, Sigurdson W \& Kuramitsu H (2005). Synergy between Tannerella forsythia and Fusobacterium nucleatum in biofilm formation. Oral Microbiol Immunol 20(1): 39-42.

26. Wang BY \& Kuramitsu HK (2005). Interactions between oral bacteria: inhibition of Streptococcus mutans bacteriocin production by Streptococcus gordonii. Appl Environ Microbiol 71(1): 354-362.

27. Stein T (2005). Bacillus subtilis antibiotics: structures, syntheses and specific functions. Mol Microbiol 56(4): 845-857.

28. Ongena $M$ \& Jacques $P$ (2008). Bacillus lipopeptides: versatile weapons for plant disease biocontrol. Trends Microbiol 16(3): 115-125.

29. Chen Y, Yan F, Chai Y, Liu H, Kolter R, Losick R \& Guo JH (2013). Biocontrol of tomato wilt disease by Bacillus subtilis isolates from natural environments depends on conserved genes mediating biofilm formation. Appl Environ Microbiol 15(3): 848-864. 